\title{
GPs at the Deep End
}

In September 2009, RCGP Scotland held an unprecedented meeting involving GPs from the 100 most deprived general practices in Scotland. It was the first time in the history of the NHS that this group had been convened or consulted.

The College had set up a working group to produce a report on what general practices in Scotland could do to address inequalities in health. The group made three early decisions. First, it would not replicate the many previous and largely ineffective reports on inequalities in health, reviewing the partial literature and drawing partial conclusions. Second, it would not issue GPs with a 'toolkit', the approach of technocrats, which assumes that GPs only need to be told what to do. Third, it would listen to what GPs from the front line had to say.

The College established a budget which would allow locum fees to be paid. After some hesitation, the Scottish Government Health Department agreed to match the College's funding. On the day, GPs from 63 of the 100 most deprived general practices attended, along with four GPs from homeless practices in Glasgow and Edinburgh, four GPs from rural practices including small areas of deprivation, and two civil servant observers. The day was spent talking, in groups and open forums, to capture the experience and views of GPs from the Deep End.

\section{THE DEEP END}

Practices had been ranked according to the proportion of the patients on their lists living in the $15 \%$ of most deprived datazones in Scotland (essentially postcodes characterised by the Scottish Index of Multiple Deprivation) - the target population for Scottish Government policies to address inequalities in health. ${ }^{1}$ Deep End practices have from $50-90 \%$ of their patients in this category, and collectively serve $50 \%$ of people living in the most deprived $15 \%$ of datazones. The other $50 \%$ is served by 700 other practices in Scotland. Thus, the Deep End project has focused on blanket deprivation, rather than pocket deprivation, on the grounds that this is where a new start needs to be made most.

The Deep End epithet arose from the observation that while the prevalence of health problems rises 2.5-3.0 fold across tenths of the socioeconomic spectrum, the distribution of GPs is almost flat. Since 1948, the NHS has supplied GPs in the same way that bread, butter, and eggs were rationed in World War 2 - everybody gets the same. In severely deprived areas this results in a major mismatch of need and resource, with insufficient time to get to the bottom of patients' problems - hence the swimming pool analogy in which GPs at the Deep End are treading water. The analogy does not imply that GPs at the Shallow End are not busy, or that they do not have demanding patients, but their patients generally live much longer and most present less complex burdens of need.

\section{THE CHALLENGE}

No one at the meeting was under any illusion about the many social determinants of poor health, and the need for measures outside general practice to protect and promote the current and future health of local populations. However, health care increasingly makes a difference to population health, ${ }^{2}$ and if this is delivered inequitably, health care can widen inequality. The challenge for health care is to find ways of increasing the volume, quality and consistency of care in deprived areas.

\section{THE PRACTICES}

Eighty-five of the top 100 practices are based in Glasgow City, with 5 in Inverclyde, five in Edinburgh, two in Dundee, two in Ayrshire, and one in Renfrewshire*. Forty-six of the practices are based in two Community Health Partnerships (CHPs), in Glasgow East and North, where they comprise $84 \%$ of all practices. The other practices are a minority of practices in the CHPs in which they are based.

* This classification was based on SIMD 2006. A revision of SIMD in 2009 added 14 new practices, mostly from outside Glasgow.
The average list size is 4316, with 20 single-handed practices and 60 with three GP partners or less. There is no difference in the number of points achieved in the Quality and Outcomes Framework (QOF) between Deep End practices and other practices in Scotland. ${ }^{3}$ About a half of practices take part in undergraduate teaching, a quarter in postgraduate training and two-thirds in research (via the Scottish Primary Care Research Network) and primary care development (via the Scottish Primary Care Collaborative).

\section{THE MEETING}

The meeting was largely based on the sharing of experience and views. Many of the participants knew each other well from other activities. However, the focus on practices serving populations with concentrated deprivation and the absence of colleagues representing other types of practice were novel. In the final session, several participants commented on the almost immediate and strong group identity of practitioners from the 100 most deprived practices and the positive, cathartic nature of the meeting.

It was clear that Scotland does not have many of the problems of general practice in deprived inner city areas, which have provided the context for much primary care development in England. Despite the heavy burden of health needs and demands, and their impact on both patients and staff, general practice serving areas of concentrated deprivation in Scotland is characterised by high quality (as measured by the QOF), high morale (as demonstrated by involvement in additional professional activities) and high commitment to improving services for patients (as evident by the discussions at the meeting). However, much more could be done.

The meeting strongly affirmed, indeed took for granted, the strengths of the general practice model, ${ }^{4}$ based on contact, coverage, continuity, coordination, flexibility, relationships, trust and leadership. There was frustration, however, from lack of resource, lack of 
support, lack of identity, and marginalisation within current NHS arrangements. A strong theme was the problematic and dysfunctional nature of many external relationships, including those with non-practice-employed staff, local authority services and community health partnerships. Many practitioners regretted the devaluing of consultations, considered to be the heart of general practice, by the financial incentives of the GMS contract introduced in 2004.

The topics selected by participants for discussion were a mixture of issues particular to deprived areas (for example mental health and addiction, patient empowerment, resource allocation, and support for practitioners) and issues of relevance to all general practices (for example, multiprofessional working, relationships with secondary care, infrastructure and premises, and relationships with CHPs).
A GP from Edinburgh commented:

'I was in groups made up entirely of non-Lothian GPs. What was striking was not only that we got on well, but on how much convergence there was in terms of the problems we face. I was in the primary/secondary care group and virtually everything said by Glasgow GPs, I could have said first about Edinburgh - to a surprising level of detail. That problems seem to be so very generic and uniform across the board hopefully means that there might be generic and uniform answers too.'

\section{WHAT NEXT ?}

The immediate challenge was to build on the engagement, enthusiasm, ideas, and precedent generated by this first meeting. Could the extraordinary nature of the meeting be made ordinary, so that the top
100 general practices become a more effective force for improving primary care? Future articles in this series will describe what happened next.

\section{Graham Watt}

On behalf of the Deep End Steering Group.

\section{REFERENCES}

1. The Scottish Government. Scottish Index of Multiple Deprivation: 2009 General Report.

http://www.scotland.gov.uk/Publications/2009/10/28 04046/1 (accessed 2 Dec 2010).

2. Bunker JP. The role of medical care in contributing to health improvements within societies. Int J Epidemiol 2001; 30: 1260-1263.

3. Mackay DF, Watt GCM. General practice size determines participation in optional activities: crosssectional analysis of a national primary care system. Prim Health Care Res Dev 2010; 11: 271-279.

4. Gillies JCM, Mercer SW, Lyon A, et al. Distilling the essence of general practice: a learning journey in progress. Br J Gen Pract 2009; 59: 356-363.

DOI: 10.3399/bjgp11X549090

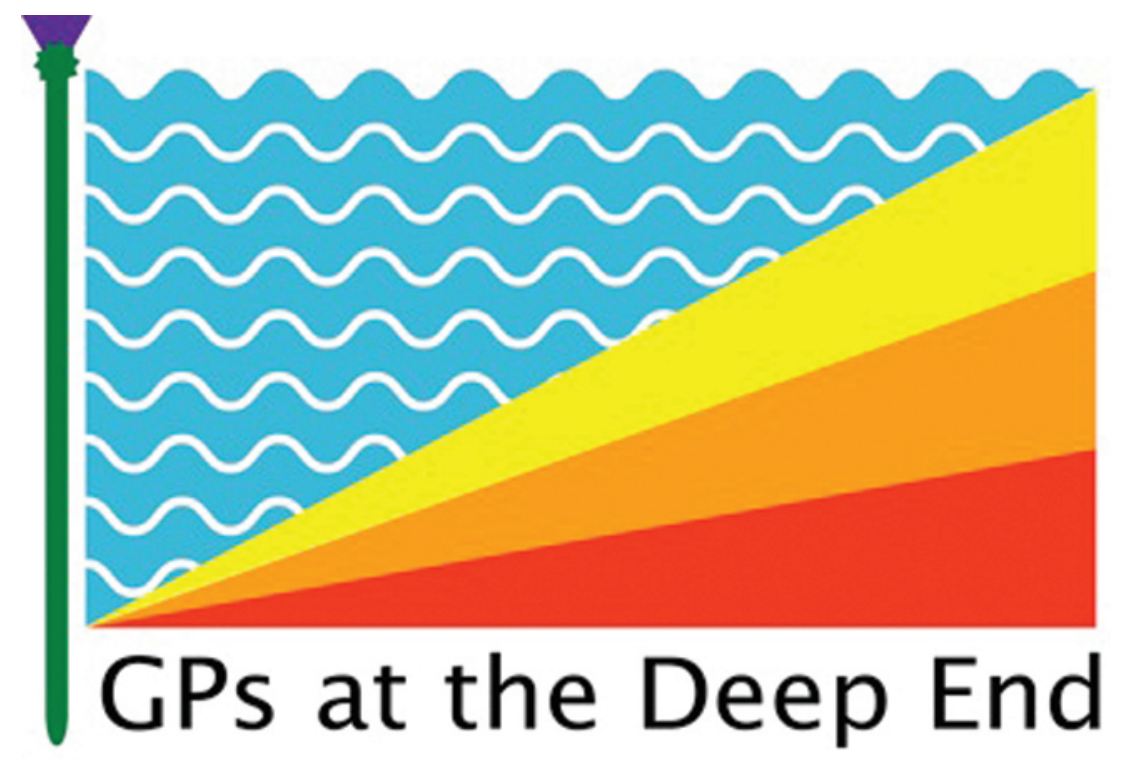

GPs at the Deep End work in 100 general practices, serving the most socioeconomically deprived populations in Scotland. The activities of the group are supported by the Royal College of General
Practitioners (Scotland), the Scottish Government Health Department, the Glasgow Centre for Population Health, and the section of General Practice and Primary Care at the University of Glasgow.
The logo includes:

- the deep end of a swimming pool;

- gradients, including the steep slope of need and the flat distribution of manpower;

- a flag to represent practitioners at the Deep End;

- a thistle;

- a spurtle (a traditional Scottish stirring instrument); and

- a sunrise.

\section{Contacts for further information Paul Alexander, RCGP Scotland palexander@rcgp-scotland.org.uk} John Budd, Lothian Deprivation Interest Group John.Budd@lothian.scot.nhs.uk

Petra Sambale, Keppoch Medical Practice,

Glasgow psambale@btinternet.com

Graham Watt, University of Glasgow graham.watt@glasgow.ac.uk

Full reports available at:

www.gla.ac.uk/departments/generalpracticeprimary care/deepend 